\title{
Augmented Reality: Prototype for the Teaching-Learning Process in Peru
}

\author{
Shalóm Adonai Huaraz Morales ${ }^{1}$ \\ Faculty of Sciences and Engineering \\ Universidad de Ciencias y Humanidades, Lima, Perú \\ Alexi Delgado ${ }^{3}$ \\ Mining Engineering Section \\ Pontificia Universidad Católica del Perú, Lima, Perú
}

\author{
Laberiano Andrade-Arenas ${ }^{2}$ \\ Faculty of Sciences and Engineering \\ Universidad de Ciencias y Humanidades, Lima, Perú \\ Enrique Lee Huamaní ${ }^{4}$ \\ Image Processing Research Laboratory \\ Universidad de Ciencias y Humanidades, Lima, Perú
}

\begin{abstract}
In recent years, augmented reality is playing an important role in the world of mobile technology, since it is a way to facilitate the teaching-learning processes, this easy teachinglearning process generates a great contribution in companies, either creating opportunities or changing the way in which companies approach and interact with their end customers, this can mean a remarkable growth of the organization, that is why in this work an augmented reality prototype has been made using the methodology Scrum at the University of Sciences and Humanities of Lima-Peru, but with a focus on the nursing career. Knowing that the problem is the limited learning that students acquire in the classrooms, for which, we want to make use of augmented reality, so that this improves the form of education that is provided to university students. The result obtained, from developing the case study, was an augmented reality prototype for the improvement of education at the University of Sciences and Humanities of Lima-Peru, which shows a virtual model (it depends on the image shown), able to interact with the user, making it attractive and motivating for the student, this prototype was achieved, using Unity (3D development platform, Vuforia (augmented reality software development kit), Microsoft Visual Studio (integrated development environment), the Scrum Methodology (Scrum Pillars, Product Backlog, Product Backlog Estimation, Speed, Backlog Prioritization and Sprint Planning) and the C\# Language (C Sharp).
\end{abstract}

Keywords-Augmented reality; teaching; education; scrum; unity

\section{INTRODUCTION}

The use of the increased reality, in the world, is one of the most modern technologies, because it is considered to be a technique that offers privileges in education, giving a high potential to this, making the learning more attractive to the students. According to the [1] that is carried out, using the increased reality, the project offers the opportunity to work with the students, to motivate them and administer them knowledge through the improvement of the teaching of the real world, with a series of virtual objects within this, creating this year, learning experiences. According to this, [2], communications between teachers and students, which, when performing activities together, serves teachers to study as students acquire knowledge in the classroom, but only, providing them with a limited vision of learning, so this study, makes a useful contribution to existing knowledge.
Likewise, in research [3], about learning, it was more likely more than $70 \%$ of students identified learning experience, as a preferred method of learning. And the research [4] has shown how it is better learned and participating in "real" tasks in practice, instead of teaching theory, this can be developed through the teaching of cognitive processes such as perception, attention, memory, and thought. This is the case, that learning [5] experience requires a repetitive process, whereby ideas are applied and tested as feedback is received for improvement. According to China [6], reports in its studies on the use of increased reality tools to develop the oral competition of students in language learning, where data was collected, recorded oral presentations, observations, and comments from students.

These results revealed, which, with the use of the augmented reality tool, obtained a higher score, which when they have not augmented reality tools, these increased reality tools, showed students a facility in learning. In Peru [7], There is a problem with education, that is why the incorporation of augmented reality is an alternative for the improvement of some concepts, in the way that teachers teach students, to generate, susceptible to use new technologies in the field of teaching, giving positive results, since the increased reality, as a complement to teaching, will be beneficial. Therefore, the importance of this work lies in the fact that, slowly, but steadily, they allow augmented reality to be established among education professionals as a strategy that can transform the education of students.

All this was done through the use of the Scrum methodology, where the Pillars of Scrum were used so that the methodology is effective at the time of implementation, the Product Backlog where the user stories were placed, Estimating the Product Backlog where each story was scored of user, Velocity where it was established how many sprints were carried out, Backlog Prioritization where the user stories were ordered by priority and Sprint Planning where the development of each sprint was planned to develop the augmented reality prototype.

The objective of this work is to make a prototype of augmented reality under the Scrum methodology to carry out a pilot with the Nursing career.

Section II explains the literature review, Section III the methodology, Section IV the results and discussions, and 
finally Section V explains the conclusions and future work.

\section{LiterATURE REVIEW}

This section explains the fundamental material for the preparation of this paper.

\section{A. Background}

A survey on augmented reality is approached, it tells us about the progress that augmented reality has had, showing us that augmented reality is compatible with many technologies [8]. It also shows us successful designs and applications of augmented reality in education, architecture and marketing aspects, in addition to dealing with important topics based on augmented reality such as augmented reality screen technologies (sensory screens), augmented reality development tools (Software frameworks, development tools and creation tools), augmented reality interaction technologies (Browsers and interfaces), interface patterns and evaluations of virtual reality systems (Methods).

This article [9] provides us with a wide range of various software development kits (SDKs) related to augmented reality, such as Metaio, Vuforia, D'Fusion, Wikitude, ARToolKit and AR-media; In order to compare them (by license, by platform, by markers and by the ability to superimpose) according to the qualities that each one of them has, it also shows us the differences between virtual reality and augmented reality, where its details are detailed. more relevant differences so that the reader can differentiate them quickly, in addition this article emphasizes the fact that mixed reality is the sum of augmented reality with virtual reality, and finally shows us how augmented reality works, teaching it in a bold way so that in this way its operation can be fully understood.

As for learning, this article [10] presents augmented reality focused on education, says augmented reality can be found in different areas, but in itself it will be more focused on education, provoked and thus generating unique environments; it also shows the uses, advantages, characteristics and effectiveness of augmented reality; He tells us about the analysis they made of augmented reality, following classifications such as countries, subject matter, type of augmented reality and research methods. To conclude, it infers us that there are numerous educational applications regarding augmented reality and that they are used in classrooms as well as abroad.

Another field in medicine, this article [11] mentions augmented reality but applied to surgery, it mentions that augmented reality can give efficiency and safety in surgical training; It also shows a scheme with basic principles of augmented reality as a basis for the reader to understand clearly and concisely "What is augmented reality?", this article mentions that the augmented reality system provides data in real time to the surgeon, Emphasizing the projection of augmented reality that can be given through the screen of computers, tablets, projectors, cameras and smart glasses, the article ends by making it clear that augmented reality is capable of revolutionizing the field of surgery.

To finish the background of the literature review section, the following article [12] will be addressed based on a survey on the applications of augmented reality, this article gives us to understand that augmented reality is capable of improving human perception by mixing objects physical of artificial ones; It also gives us an apex of the initial applications that augmented reality addressed, these being medicine, manufacturing and repair, annotation and visualization, robot route planning, military applications and finally entertainment, as well as those initial applications Over time applications such as tourism, architecture, cultural heritage (Museums) and education were added; To finish this article, mention that augmented reality is related to miniaturization.

\section{B. Related Work}

In this article [13], the use of mixed reality for the development of an Augmented Paper Map (APM) system was observed, the two authors who developed this article report Scrum, as the methodology that helped them to achieve the objectives of their article, explaining a bit about the roles and artifacts that were useful for the application of this methodology, they also express the design philosophy they used, which is that the design is user-centered, so that in this way the final product complies with the needs of these (Users), and thus achieve the greatest satisfaction with the minimum effort on the part of the user. It also tells us about the activities that they had to develop and carry out during the course of the article, as well as the exploration, analysis and evaluations that they had to develop for the development of the Augmented Paper Map (APM) system.

The mention of games is observed, it tells us drastically how the game is encompassed in the lives of human beings, it also mentions mixed reality but in the approach of games [14], it tells us like the previous article the use of Scrum , but focusing on the MVCE architecture (Model-View-ControllerEnvironment), which is nothing more than the MVC architecture (Model-View-Controller), but adding an "Environment" component. It also highlights the design of a mixed reality, but based on the independence of the device, the adaptive presentations and the updates of the context with respect to the game, as well as its philosophy of design centered on the user, which achieves a better experience for the game. (User) only with minimal effort.

As the clear examples of the application of the Scrum methodology, now there is a combination of the Scrum methodology with the extreme programming methodology (XP), which is focused on virtual reality. This article [15] shows us the use of a video game engine known as Unity, the Scrum plus XP combination to use it as a methodology as mentioned before and the objective of the article, which is the creation of virtual reality for the training of technicians and industrial operators. They focus on using virtual reality as an economical alternative to using and damaging expensive industrial equipment, so their objective is focused on two scenarios: instrument recognition activity (HART Device) and training activity (Installation, connection, basic and advanced settings).

Virtual reality focused on agile development, this article [16] shows the explanation of the use of the Scrum methodology, as well as the explanation of the use of the extreme programming methodology (XP), the principles of the agile manifesto are also covered, the life cycle of Scrum and extreme 
programming (XP), the systems developed based on virtual reality, the application of agile methodologies in virtual reality and to finish they propose a process of development of virtual reality systems based on eight activities main (Definition of user stories, architectural peak, elucidation of interactivity requirements, iteration planning, peak, development, integration tests and customer tests).

\section{Methodology}

In this section, the methodology that was carried out was explained, in the augmented reality prototype using Unity, the Scrum methodology was carried out, for the improvement of education at the University of Sciences and Humanities in Lima-Peru, thus achieving the objectives, with support of this methodology [17] that is shown in Fig. 1.

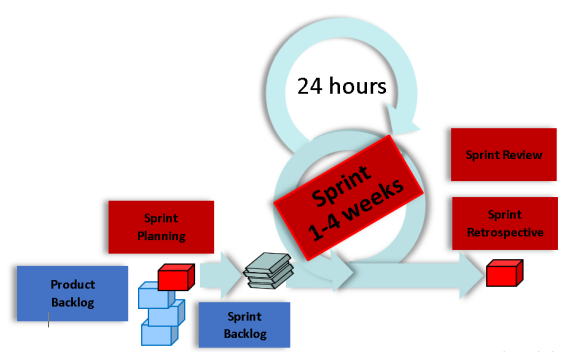

Fig. 1. Scrum Agile Methodology for the Augmented Reality Prototype.

As mentioned the prototype was made in Unity, which is a 3D development platform, to develop a variety of simulations, in games (developers of games), AEC (architecture, engineering, and construction), cars, and cinematographies [18]. And it is used, Vuforia (augmented reality software development kit), which is, one of the most popular to introduce the increased reality, Vuforia (augmented reality software development kit) uses vision technology to recognize and track images in realtime.

The increased reality based on Vuforia (augmented reality software development kit), takes the display of the device screen, as a "medium" to connect it to the world of the increased reality. What it does, is to show the images of the real world in the Camera of the corresponding device, adding the virtual objects $3 \mathrm{D}$, in the images of the real world, what it does, that is a combination, of a feeling of immersion towards the world of the increased reality, also, to develop the programming in the prototype will be used the Microsoft Visual Studio integrated development environment, using programming language C\# (C Sharp) [19].

\section{A. Scrum}

Scrum won't tell you exactly what to do, what it means, that can be done differently, as your merits, that is why the "power" is in us, to adapt it to a specific situation, and is here, where everything starts.

1) Pillars of Scrum: In the Fig. 2 the three pillars (transparency, inspection, and adaptation) that sustains SCRUM, the first pillar, the transparency, gives a clear vision to all the interested parties of the project, customers, users, sponsors, investor, among others. It tells us that clear agreements must be reached on what must be delivered or informed to the interested parties, being thus, trancing and sincere, of "how much has been advanced?", "What is it will be achieved?" and "What will not be achieved?". Inspection, the second pillar, is where the project checks, to know if the established goals are being fulfilled and if there are problems or any deviation, to be able to correct them at the time.

In Scrum there are meetings such as the diary scrum (it is done when starting the day), or the retrospective (checking at the end of each sprint), this is done to know "What has been done?", "What problems have been?" and "What is going to do today?" That's why it can be said that in Scrum if there is a "constant inspection". Adaptation, the third pillar, means those that change is welcome, and this is so, to be able to minimize the problems that are generated in the future so that in this way, continue to provide the maximum value to the client, to the business, and/or to what is developing [20].

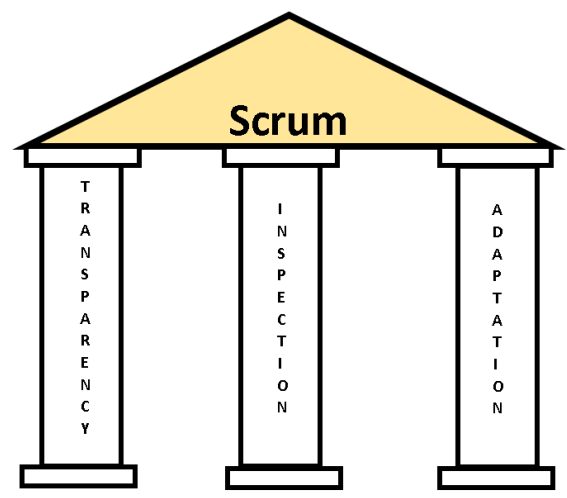

Fig. 2. The Three Pillars of Scrum.

2) Project Charter: Table I shows the Project Charter, which describes the objectives to be achieved in the project, it is here, where it is defined that the agile methodology is used., specifying the acceptance criteria for this one. In this Project Charter, the following questions are answered (Who?, What?, Where?, When?, Why? and how?), And is it here, where you can use the tool known as "Elevator Pitch", to perform the Project Charter [21].

TABLE I. Project Charter

\begin{tabular}{|c|c|}
\hline For & Target customer \\
\hline Who & $\begin{array}{l}\text { Need (Opportunity } \text { or } \\
\text { problem) }\end{array}$ \\
\hline He & Product / Service name \\
\hline What is it & Product Category \\
\hline For & $\begin{array}{l}\text { Key benefits / Reasons to } \\
\text { buy it }\end{array}$ \\
\hline Is not equal to & $\begin{array}{l}\text { Main competencies or al- } \\
\text { ternatives }\end{array}$ \\
\hline We & Definition \\
\hline
\end{tabular}

3) Product Backlog: Fig. 3 shows us the backlog prioritized, this is achieved, when performing meetings with the owner of the product, and thus generate the stories of users and prioritized (functionalities, epic, user stories), in addition to focusing on business terms, you are to be built in a short time, conducting valuable features for customers [22]. 


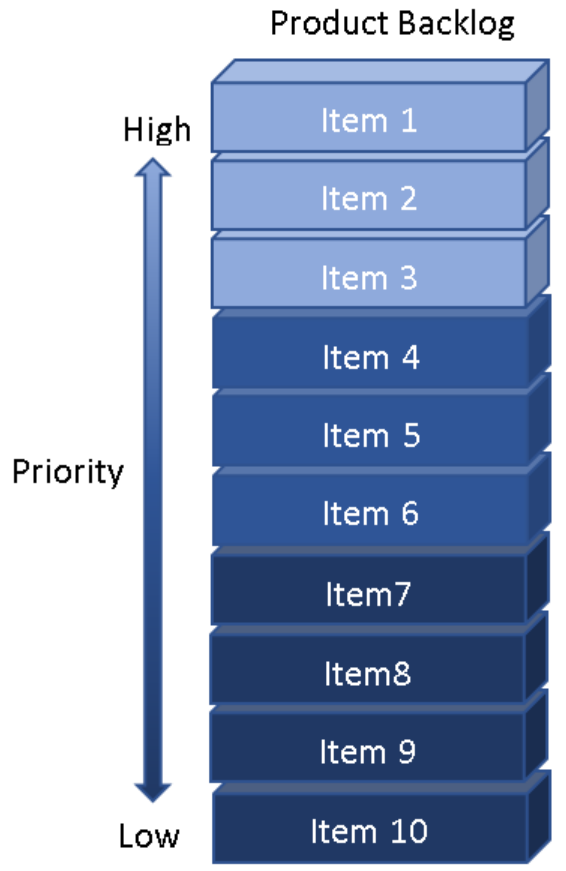

Fig. 3. Product Backlog.

4) Estimating the Product Backlog: Fig. 4 shows us how it would be an estimate of the Product Backlog, indicating its story points (sp), stories, must be reasonable, and these estimates can be generated with various tools, such as the size of your shirts, analogous estimate, Delphi and/or Planning Poker [23].

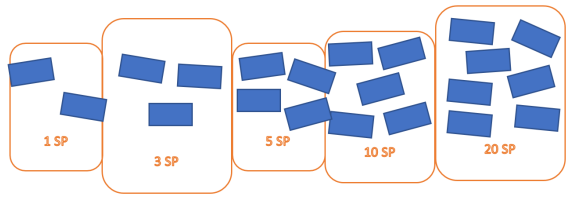

Fig. 4. Estimating the Product Backlog.

5) Velocity: In Scrum the speed is used, to define how many Sprints have, and this is, in function to speed, which is the stories of stories (necessary effort, with which the user stories were estimated) that a development team performs in each sprint. This speed may vary in each sprint, as shown in Fig. 5, wherein the chart of columns grouped in 3D, observed that the speed varies or changes by Sprint [24].

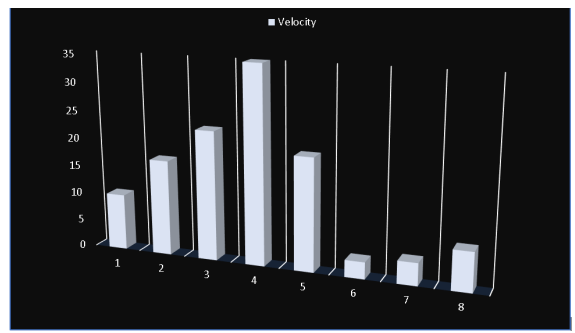

Fig. 5. Estimate Sprint Velocity.
6) Backlog Prioritization: In Fig. 6, the map of the story is displayed, which serves to prioritize the Product Backlog, the structure of this is the same as that of the Road Map, where its columns are the software or project modules, and where the first row is the backbone (most importantly, if this is not done. No system), the second row is the walking skeleton (Minimum viable product, which means, the most valuable functionality for the user, and the one that will give it to the system), and the following rows range from the most important user stories, at least important [25].

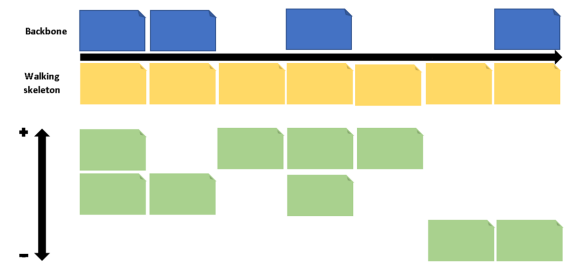

Fig. 6. Map of the Story.

7) Sprint Planning: In Fig. 7, it is observed that the structure of the Road Map [26], is the same as that of the map of the story, this is the map of the story sorted by delivery (Sprint set) or by Sprint (1 to 4 weeks), according to one establishes it, and is used to plan the Sprint. After performing the sprint planning, the user stories of the Sprint are selected to work, you are user stories will be developed, in a format of user stories, already established by the person in charge, as shown in Fig. 8, which has fields such as, the developer, the estimated time, the description of the user story, tests, tasks and finally the prototype; this format may vary [27].

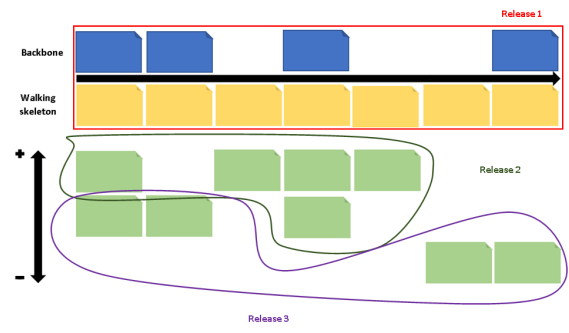

Fig. 7. Road Map.

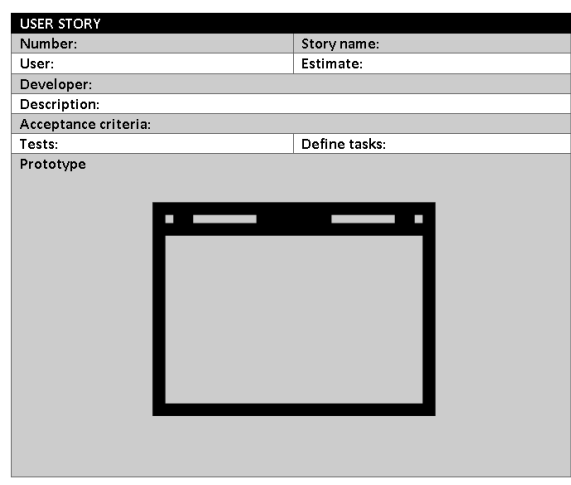

Fig. 8. User Story Format. 


\section{B. Tools and Programming Language to Develop the Proto- type}

In this section, it was detailed, the tools to be used to develop the prototype of increased reality focused on improving teaching at the Universidad de Ciencias y Humanidades, as well as the programming languages to be used.

1) Unity: Unity is a 3D development platform, which gives us everything we need to be able to develop a variety of functionalities, such as simulating the laws of physics, adding animations, adding sounds and programming; This platform supports the $\mathrm{C \#}$ ( $\mathrm{C}$ sharp) programming language, in addition to having an Assets (resource) library known as the Asset Store of Unity, where you can find textures, animations and models ready to use in Unity [28].

2) Vuforia: To introduce the augmented reality, Vuforia (augmented reality software development kit) was used, since this uses vision technology to recognize and track the images in real-time, taking the display of the screen of the devices as a "medium" to connect it with the world of the increased reality. Vuforia (augmented reality software development kit), It serves us to generate a license key, which will help us load the database created in Vuforia (augmented reality software development kit) in Unity, to generate the augmented reality [29].

3) Microsoft Visual Studio: It is an integrated development environment (IDE) that supports several programming languages $(\mathrm{C}++, \mathrm{C} \#$, Visual Basic .Net, F\#, Java, Python, Ruby and PHP), this IDE gives developers the ability to create websites ( Collection of web pages); Knowing that this IDE includes the C\# (C Sharp) programming language, this is beneficial for this article, since the $\mathrm{C \#} \mathrm{(C} \mathrm{Sharp)} \mathrm{programming}$ language was used for the development of the augmented reality prototype [30].

4) C\#: For the development of this augmented reality prototype, the programming language C\# (C Sharp) was used, this programming language C\# (C Sharp) can be used in several integrated development environments (IDE), such as Microsoft Visual Studio, ShardDevelop, QuickSharp, xacc.ide, MonoDevelop, and Xamarin Studio (XS); Since this programming language is compatible with Unity, this was the one that was used to give interactions of the "models" with the user, to achieve a kind of "communication" between the prototype and the user [31].

\section{Development of the Methodology}

According to the methodology mentioned above, and the processes that were detailed in it, the development of the prototype will be implemented, based on the increased reality for the teaching of the courses of certain professional schools of the Universidad de Ciencias y Humanidades.

1) Product Backlog: In this section can observe the user stories that were developed to develop the prototype:

- User Story 1: As the director, I want to visualize a model that is related to a university course to be able to better explain the class.

- User Story 2: As the director I want to visualize multimedia content that is related to a university course to convey knowledge to students.
- User Story 3: As the director I want the prototype to be used in smartphones to have quick access to it.

- User Story 4: As the director I want the prototype to be interactive with the user to improve the education process.

2) Estimating the Product Backlog: To estimate the stories of users who were placed on the product stack (Product Backlog), a technique known as planning poker is going to be used, but not the planning poker is known as such, but a variant of it is, which works with the Fibonacci Sequence, which will be explained below. The Planning Poker has about eight "cards" $(1 / 2,1,2,3,5,6,7, \infty)$, without counting the "card" of doubt and rest, while the variance of the planning poker that goes from hand with the Fibonacci Sequence works with ten "cards" $(0,1 / 2,1,2,3,5,8,13,21, \infty)$, which will help us give you a "score", to each user story. The user's stories were beginning to be story through story (necessary effort), using the variation of Planning Poker, who works with the Fibonacci Sequence, was taken as a reference The user story that it is less than to make, making a "score" of "2" story points (necessary effort) and thus continue to find the estimates of the remaining user stories.

3) Determination of Speed: Here it is defined, how many sprints will be done, for this, first a "10" speed was determined, without forgetting, that each Sprint has user stories and these are in turn, they have "activities", and these "activities" are expressed in time (hours), which cannot exceed 4 weeks, since that deals with the agile methodologies, which each Sprint is completed from 1 to 4 weeks. After that, the sum of the story points was divided (necessary effort) of the user stories that were placed in the Product Backlog, between the certain speed which originated us "2.8", but when rounding it gives us " 3 ", which means that for the prototype of this work have "3 Sprint". At the beginning of the first sprint, it was started with a speed of "10", which has a sum of "13" story points (necessary effort), and then, as it was advanced in the Sprint, this speed was changing, reaching the second Sprint, with a speed of "7", and with a sum of points of story (necessary effort) of "7", already in the last of the Sprint, the third Sprint, the speed was maintained in "7", and with a total amount of story points (necessary effort) " 8 ".

4) Prioritizing the Backlog: In this section, the backlog is prioritized, depending on the value given to the business, this is where, use the tool known as the map of the story, to generate the prioritization of the backlog. This map of the story, gives us an overview of "What is to do first?", and "What is to do after?". In the development of the map of story, it began, with the backbone that is the first "row" of the map of story, where it was placed, the essential user stories (as the director I want to visualize a model that is related to a course of the university to be able to better explain the class, as the director I want to visualize a multimedia content that is related to a course of the university to transmit knowledge to the students), to give improvement to education, then on the second "row", that of the walking skeleton was placed, the user story that gives the most valuable functionality for the user (as the director I want the prototype to be interactive with the user to improve the process of education), to end this section, in the last "row" remained the remaining user stories, ordered more important, 
unless important (as the director I want the prototype to be used in smartphones to have quick access to it).

5) Sprint Planning: To plan the Sprint, the technique known as road map was used, as mentioned, in the methodology of this work, could be said that the path of the product, is originated from the map of the story. To start with this, the map of the story is taken, and starts to choose from, that user stories that was planned by Sprint.

6) Sprint Backlog:

- Sprint 1: In the first Sprint, as mentioned in the section of the speed determination, it was started with a "10" speed, making the user stories corresponding to this (as the director I want to visualize a model that is related to a course of the university to be able to better explain the class), for which, Unity is used, which is a 3D development platform, and Vuforia (augmented reality software development kit), to introduce the augmented reality, to which you ensemble the renovated reality, since this, uses vision technology to recognize and track the images in realtime, taking the visualization of the screen of the devices as "Medium" to connect it with the world of the increased reality, finally for this Sprint used web platforms used as free $3 \mathrm{~d}$, to find and download 3D models, and find and download 3D models. In the first Sprint, in summary, what was done, was that the virtual 3 "objects" were added, to the 3D development unit platform, modifying the "object", since some of the components of the "object", not use it, it should be highlighted, that this modification was done in Unity, and the result of this, can observe it in Fig. 9.

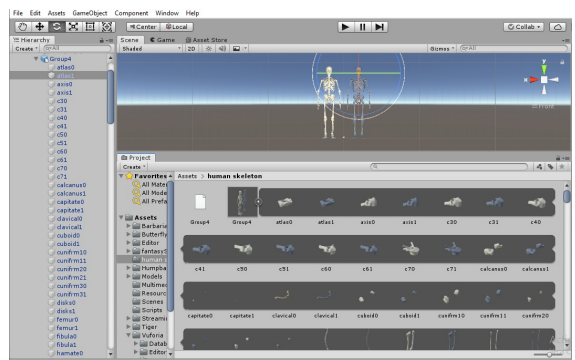

Fig. 9. Sprint 1 - User Story 1.

- $\quad$ Sprint 2: In the second Sprint, as mentioned in the section of the determination of the speed, it was begun with a "7" speed, making the user stories corresponding to this (as director I want to visualize a multimedia content that is related to a course of the university to convey knowledge to students, as director I want the prototype to be used in smartphones to have quick access to it), for which, Unity, Vuforia (augmented reality software development kit) was used and videos. To start with the second Sprint, in summary, what was done, was that the videos were added to 3D objects that can be created in Unity, the result of this can be seen, in Fig. 10, also, Unity (3D development platform) was used, so that the prototype can be used in smartphones, as can observe, in Fig. 11.

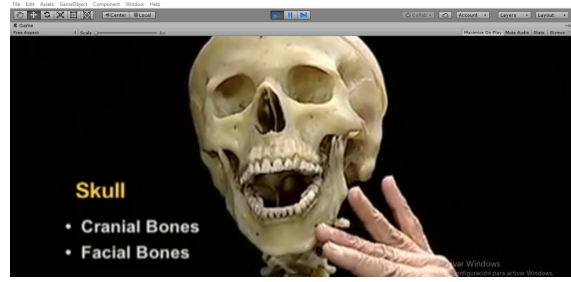

Fig. 10. Sprint 2 - User Story 2.

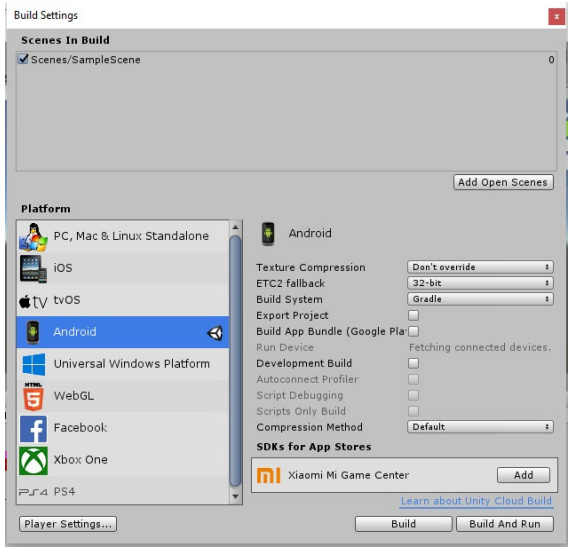

Fig. 11. Sprint 2 - User Story 3.

- Sprint 3: In the third and last sprint, as mentioned in the section of the determination of the speed, it remained with a speed of "7", making the user stories corresponding to this (as the director I want the prototype to be interactive with the user to improve the process of education), for which, Unity, Vuforia (augmented reality software development kit) was used, videos and the Microsoft Visual Studio integrated development environment. In the third, and last sprint, in summary, what was done, was that the Microsoft Visual Studio development environment was used to program, using programming language $\mathrm{C \#}$ ( $\mathrm{C}$ sharp), added this, to videos and models, to achieve that both the video and the model are interactive with the user, the result of this, can observe it in Fig. 12.

7) Sprint Review: This meeting was made at the end of each Sprint, to check how the objectives are being developed, it is meeting one hour by Sprint. Here what was done is to review the progress to reach the prototype, identified what was achieved, as well as what was not achieved, and is here where the operation of the end is shown in the Sprint.

8) Sprint Retrospective: This meeting, was made to give improvements to the following Sprint as it was moving forward, it should be noted, that this meeting was held after the Sprint Review with a duration of an hour, and is here where some questions were made ("worked on the last Sprint?", "What will be improved in the following Sprint?" and "What problems have been had in the progress of the development of the prototype?"), and at the end of the recommendations, the improvement was given to the following Sprint. 


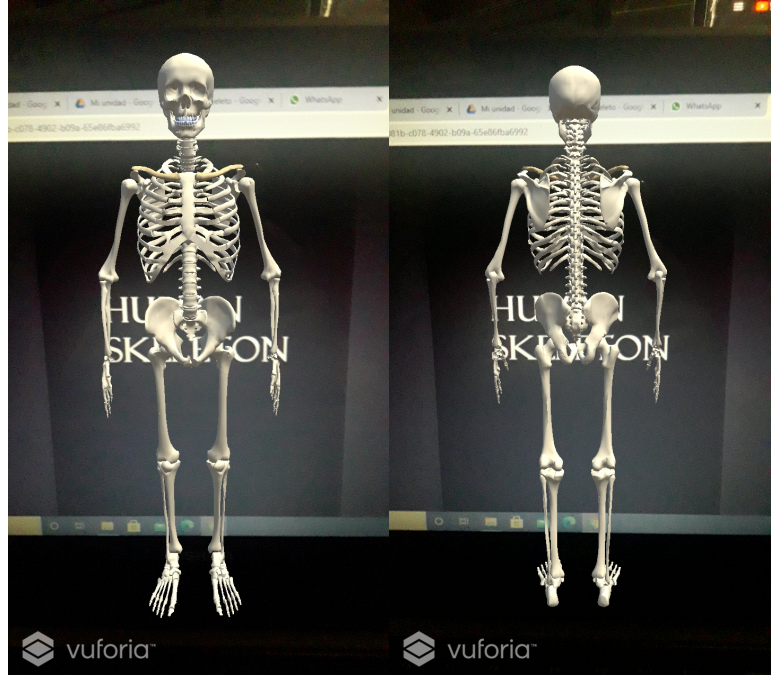

Fig. 12. Sprint 3 - User Story 4.

\section{Testing}

This section shows the survey administration software known as Google Forms, which can be seen in Fig. 13, where a survey was carried out among the students of the Faculty of Health Sciences of the Professional School of Nursing, in the It shows four short answer questions which are "What is your opinion about virtual reality?", "Would you like to visualize through the Smartphone 'objects' in 3D dimension?", "Are you likely to use this application?" and "Does its implementation seem correct?"; as well as a box question which is "For what course would you like this application?" This survey is key to the objective proposed in this paper, since the implementation of the prototype is focused on improving the teaching of the University of Sciences and Humanities, therefore, the opinion of the students cannot go unnoticed, since These are the ones that will handle the application, since this "application" is still a prototype, this does not evade the importance of the student's perception of virtual reality, because in the end it is for the student to feel satisfied with this implementation versus education, and thus goal-focused improvement is achieved.

Here is the before and after obtained from the Human Anatomy course, as shown in Table II, in the question "From traditional to automated", "From normal teaching to remote teaching" and "Contribution to the nursing career".

TABLE II. BASE LINE (BEFORE - AFTER)

\begin{tabular}{|l|l|}
\hline $\begin{array}{l}\text { Before human anatomy } \\
\text { course }\end{array}$ & $\begin{array}{l}\text { After human anatomy } \\
\text { course }\end{array}$ \\
\hline Traditional & Automated \\
\hline Normal Teaching & Remote Teaching \\
\hline $\begin{array}{l}\text { Contribute to the nursing } \\
\text { career community }\end{array}$ & $\begin{array}{l}\text { Contribute to the nursing } \\
\text { career community in these } \\
\text { times of pandemic }\end{array}$ \\
\hline
\end{tabular}

\section{RESUlt AND Discussion}

In this section, the results of the case study should be shown, such as that of the Scrum methodology, used in this work.

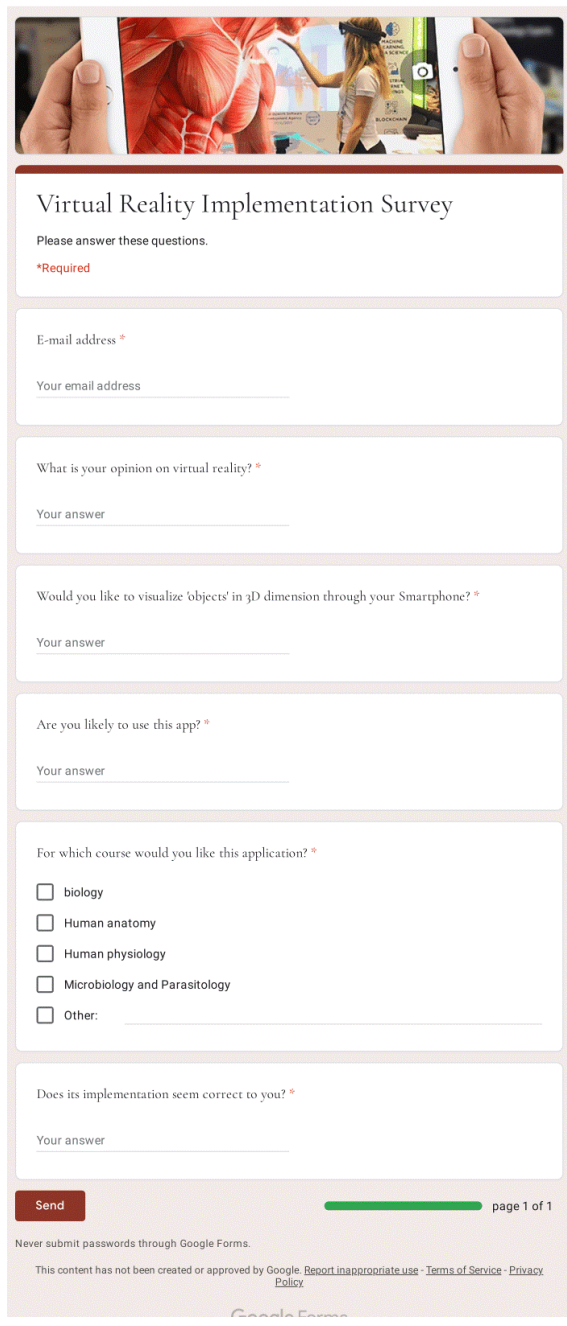

Fig. 13. Student Survey.

\section{A. About the Survey}

The survey carried out previously establishes specific questions, which can be observed in this subsection, but with the difference that the results obtained from each question asked in the survey are shown here, as shown in Table III, in the question "What is your opinion on virtual reality? "can observe a $48.1 \%$ knowledge about virtual reality by nursing students, while a higher number still do not know its meaning, in the question "Would you like to visualize 'objects' in 3D dimension through your Smartphone?" a low percentage of "37.8\%" is established in the question "Are you likely to use this app?" A high interest in the application is observed since they find it curious to see how this prototype would perform in education, in "For which course would you like this application?", have varied percentages, since it is in a box question, these Results are respectively set to the boxes of question 4 shown in Fig. 13 and to finish a large number of students are observed who consider the implementation of this prototype correct.

The results of a survey carried out in the organization towards the General Manager, Coordinators, School Directors and the Dean are also observed, as shown in Table IV, in 
TABLE III. SURVEY RESPONSE

\begin{tabular}{|c|c|}
\hline Questions & Answers \\
\hline $\begin{array}{l}\text { What is your opinion on } \\
\text { virtual reality? }\end{array}$ & $48.1 \%$ \\
\hline $\begin{array}{l}\text { Would you like to visual- } \\
\text { ize 'objects' in 3D dimen- } \\
\text { sion through your Smart- } \\
\text { phone? }\end{array}$ & $37.8 \%$ \\
\hline $\begin{array}{l}\text { Are you likely to use this } \\
\text { app? }\end{array}$ & $89.9 \%$ \\
\hline $\begin{array}{l}\text { For which course would } \\
\text { you like this application? }\end{array}$ & $\begin{array}{l}95.7 \%, 85.4 \%, 80.2 \% \text {, } \\
86.5 \% \text { y } 86.1 \%\end{array}$ \\
\hline $\begin{array}{l}\text { Does its implementation } \\
\text { seem correct to you? }\end{array}$ & $94.3 \%$ \\
\hline
\end{tabular}

the question "Are you satisfied with the scrum methodology carried out in the prototype?", Where a $65 \%$ acceptance is observed; in the question "Would you recommend using the scrum methodology for other projects?", where a $75 \%$ acceptance is observed; and to finish in the question "Do you think that Scrum methodology is better than the traditional methodology used in the university?", an $80 \%$ acceptance is observed.

TABLE IV. ORGANIZATION SURVEY

\begin{tabular}{|l|l|}
\hline \multicolumn{1}{|c|}{ Questions } & \multicolumn{1}{|c|}{ Answers } \\
\hline $\begin{array}{l}\text { Are you satisfied with the } \\
\text { scrum methodology car- } \\
\text { ried out in the prototype? }\end{array}$ & $65 \%$ \\
\hline $\begin{array}{l}\text { Would you recommend us- } \\
\text { ing the scrum methodol- } \\
\text { ogy for other projects? }\end{array}$ & $\mathbf{7 5} \%$ \\
\hline $\begin{array}{l}\text { Do you think that Scrum } \\
\text { methodology is better than } \\
\text { the traditional methodol- } \\
\text { ogy used in the university? }\end{array}$ & $\mathbf{8 0} \%$ \\
\hline
\end{tabular}

\section{B. About the Case Study}

In the case of study, which deals with the development of the prototype of augmented reality, for the improvement of the teaching of certain courses of the professional schools of the University of Sciences and Humanities of Lima-Peru, was developed based on the Scrum methodology [32], which helped, on the process of development of the prototype as a "guide", since we showed the way for which it should advance for this development, this path can be observed and read in section 3 (case study) of this work, the 3D development platform was also used, the Unity [33], this being a good platform for the proposed in this work since the prototype was developed, thanks to this platform, as shown in Fig. 9, Fig. 10, Fig. 11 and Fig. 12 of point 6 (Sprint Backlog) of the SCRUM subsection belonging to the case of study, where it is observed, that in each of the Sprint it was vital, use the 3D replacement platform, for which, it could be said, that this platform is the center, of everything that was used, for the goal of this work, it should be noted that this 3D development platform, Unity, has a shop known as "Asset Store of Unity" to download models, textures and animations, and thus facilitate the process of development of the prototype, since if we find the model we require, it can be imported, and use it at the time, another platform, which was used, were the web platforms such as free3d, to find and download 3D models, it was used, because in this, it is easier to find models that are required, since unlike "Asset Store of Unity", this is organized by categories (architecture, vehicles, characters, aircraft, furniture, electronics, animals, plants, weapons, sports, food and anatomy), it should be noted that as it is a model already created, Unity was used to modify it to the convenience of the prototype, as shown in Fig. 9, where a model containing two human skeletons, that of the left of an approximate color to the Black Squeeze is observed, which resembles the color of the bone, which we will need and the one of the right of the grayish blue color, which we will not need, so, we have to modify in Unity, this model that contains two human skeletons, also for the development of the prototype, was used, Vuforia (augmented reality software development kit) [34], to introduce the augmented reality, as it was mentioned, in the development of the study case, this is perfect for recognizing and tracking the images in real time, taking the display as "medium", to connect it with the world of the augmented reality, this can be seen in Fig. 12, where Vuforia (augmented reality software development kit) is doing their work, by recognizing and tracking in real time, the "Human Skeleton" image (behind the model), and connect it with the model of human skeleton, thus generating the augmented reality, which is key to this prototype, since the "essence" of this work, is the creation of a prototype of augmented reality, Vuforia (augmented reality software development kit) was used, since its handling is easy, apart from providing us with a database, where the images that will be tracked, to generate the augmented reality, and finally, for the development of the prototype, the Microsoft Visual Studio integrated development environment was used, in order to be programmed in C\# language (C sharp), since it was wanted, that the prototype has interactions with the user. All mentioned in this subsection of "Results and Discussions", was made, to achieve good control and result in the development of the prototype.

\section{About the Methodology}

The method of scrum [35], was very helpful, as we guide us, in the development of the prototype, to start, helped us to focus requirements, thanks to user stories, also, to estimate these stories, to know what the user's stories that are found to make them more, as those that were easier to develop, they also helped us, namely what amount of effort necessary we could do by Sprint, this became known, thanks to the determination of the speed; And thanks to the prioritization part of this methodology, where the story map was used, it was possible to know which user stories are more important for the prototype and which stories are less important, on the other hand, the path or route of the product was also used to know how much sprint, and which user stories are going to be done by sprint, and at the end of each sprint was made a review to see if the objectives were achieved, as well as, At the end of each sprint review, the feedback was used for continuous improvement.

- Benefits: The benefits offered by the Scrum methodology are varied [36], since when deciding to make the prototype using an agile methodology, it allows us to have a finished "product" in less time than when choosing a traditional methodology, that's why, here, we are dealing with specific things, which strengthened the development of the prototype, that's why we 
will start with the speed, which made us know, how much effort was invested per sprint, but this, depending on the performance, that is giving the sprint. Also, thanks to the Scrum methodology, the development of the prototype could be divided into parts, thus generating a "finished product" by sprint. On the other hand, another benefits of the scrum methodology is the sprint review, as this helps us to verify the achievement of the goal, identifying what was achieved, as well as what was not achieved, and finally, the feedback sprint, offered by the scrum methodology, is good, as this allows us to make improvements towards the following sprint.

- Comparison: If compare the scrum methodology, with the methodology RUP (rational unified process) [37], can say, that the methodology RUP (rational unified process), is rigid, meaning that if the customer wants a change, it is very difficult to make it, since you follow the plan until the end of the project development, whereas in the Scrum, this is possible, because, scrum is flexible to change, another comparison, you can make, The reason for this is that, in the methodology RUP (rational unified process), the project is conceived as one, while in scrum the project is divided into parts. It can also be said that in the methodology, the deliverable is at the end of the entire project development, while in scrum the delivery is constant [38]. This comparison of Scrum and RUP can be seen in Table V.

TABLE V. Scrum VS TRaditional Methodology RUP

\begin{tabular}{|l|l|}
\hline \multicolumn{1}{|c|}{ SCRUM } & \multicolumn{1}{c|}{ RUP } \\
\hline Accept changes & Resists changes \\
\hline Its development is flexible & Its development is rigid \\
\hline $\begin{array}{l}\text { The client is part of the } \\
\text { development team }\end{array}$ & $\begin{array}{l}\text { Customer communicates } \\
\text { with development team }\end{array}$ \\
\hline $\begin{array}{l}\text { Client available through- } \\
\text { out the project }\end{array}$ & $\begin{array}{l}\text { Client available at the be- } \\
\text { ginning of the project }\end{array}$ \\
\hline $\begin{array}{l}\text { Value is delivered to the } \\
\text { customer early }\end{array}$ & $\begin{array}{l}\text { Value is delivered to the } \\
\text { client at the end of the } \\
\text { project }\end{array}$ \\
\hline
\end{tabular}

\section{CONClusion ANd Future Work}

This augmented reality prototype has been developed satisfactorily, and thus this will help to improve the teaching in the Universidad de Ciencias y Humanidades, since this augmented reality prototype, by teaching through cognitive processes, is suitable for courses in biology, human anatomy, human physiology, microbiology, and parasitology, belonging to the professional school of nursing. The tools used for the development of this prototype were efficient and valuable, both in the use of the 3d development platform, in the ability to introduce augmented reality, and in the interactions of the "models" with the users. And the methodology used, the scrum, was very efficient, for the development of the prototype, being the scrum processes, key, to achieve the goal set, and thus ensure the development of the prototype. In future research, a menu system could be implemented for the prototype, which has options, so that the users, can know, how the prototype is used, which will show the scanned images, and thus, achieve a better understanding with the user.

\section{REFERENCES}

[1] P. P. Nechypurenko, T. V. Starova, T. V. Selivanova, A. O. Tomilina, and A. Uchitel, "Use of augmented reality in chemistry education," in
Proceedings of the 1st International Workshop on Augmented Reality in Education Kryvyi Rih, Ukraine, October 2, 2018, no. 2257. CEUR Workshop Proceedings, 2018, pp. 15-23.

[2] J. Garzón, J. Pavón, and S. Baldiris, "Systematic review and metaanalysis of augmented reality in educational settings," Virtual Reality, vol. 23 , no. 4 , pp. 447-459, 2019.

[3] S. H. Halili, "Technological advancements in education 4.0," The Online Journal of Distance Education and E-Learning, vol. 7, no. 1, pp. 63-69, 2019.

[4] A. Syawaludin et al., "Development of augmented reality-based interactive multimedia to improve critical thinking skills in science learning." International Journal of Instruction, vol. 12, no. 4, pp. 331-344, 2019.

[5] N. Elmqaddem, "Augmented reality and virtual reality in education. myth or reality?" International journal of emerging technologies in learning, vol. 14, no. 3, 2019.

[6] M.-P. Chen, L.-C. Wang, D. Zou, S.-Y. Lin, H. Xie, and C.-C. Tsai, "Effects of captions and english proficiency on learning effectiveness, motivation and attitude in augmented-reality-enhanced theme-based contextualized efl learning," Computer Assisted Language Learning, pp. 131, 2020.

[7] P. Chen, X. Liu, W. Cheng, and R. Huang, "A review of using augmented reality in education from 2011 to 2016," Innovations in smart learning, pp. 13-18, 2017.

[8] D. Chatzopoulos, C. Bermejo, Z. Huang, and P. Hui, "Mobile augmented reality survey: From where we are to where we go," IEEE Access, vol. 5, pp. 6917-6950, 2017

[9] A. Hanafi, L. Elaachak, and M. Bouhorma, "A comparative study of augmented reality sdks to develop an educational application in chemical field," in Proceedings of the 2nd International Conference on Networking, Information Systems \&amp; Security, ser. NISS19. New York, NY, USA: Association for Computing Machinery, 2019. [Online]. Available: https://doi.org/10.1145/3320326.3320386

[10] H. Altinpulluk, "Determining the trends of using augmented reality in education between 2006-2016," Education and Information Technologies, vol. 24, no. 2, pp. 1089-1114, 2019.

[11] P. Vávra, J. Roman, P. Zonča, P. Ihnát, M. Němec, J. Kumar, N. Habib, and A. El-Gendi, "Recent development of augmented reality in surgery: a review," Journal of healthcare engineering, vol. 2017, 2017.

[12] L. F. de Souza Cardoso, F. C. M. Q. Mariano, and E. R. Zorzal, "A survey of industrial augmented reality," Computers \& Industrial Engineering, vol. 139, p. 106159, 2020. [Online]. Available: https://www.sciencedirect.com/science/article/pii/S03608 3521930628X

[13] G. Ameri, J. S. Baxter, D. Bainbridge, T. M. Peters, and E. C. Chen, "Mixed reality ultrasound guidance system: a case study in system development and a cautionary tale," International journal of computer assisted radiology and surgery, vol. 13, no. 4, pp. 495-505, 2018.

[14] M. Cowling, M. Hillier, and J. Birt, "Integrating mixed reality spatial learning analytics into secure electronic exams," in International Conference on Innovation, Practice and Research in the Use of Educational Technologies in Tertiary Education. ASCILITE, 2018, pp. 330-334.

[15] E. Lozada-Martinez, J. E. Naranjo, C. A. Garcia, D. M. Soria, O. R. Toscano, and M. V. Garcia, "Scrum and extreme programming agile model approach for virtual training environment design," in 2019 IEEE Fourth Ecuador Technical Chapters Meeting (ETCM), 2019, pp. 1-5.

[16] T. Riemann, A. Kreß, L. Roth, S. Klipfel, J. Metternich, and P. Grell, "Agile implementation of virtual reality in learning factories," Procedia Manufacturing, vol. 45, pp. 1-6, 2020, learning Factories across the value chain - from innovation to service - The 10th Conference on Learning Factories 2020. [Online]. Available: https://www.sciencedirect.com/science/article/pii/S23519 78920310672

[17] S. M. Saleh, S. M. Huq, and M. A. Rahman, "Comparative study within scrum, kanban, xp focused on their practices," in 2019 International Conference on Electrical, Computer and Communication Engineering (ECCE), 2019, pp. 1-6.

[18] A. Juliani, V. Berges, E. Vckay, Y. Gao, H. Henry, M. Mattar, and D. Lange, "Unity: A general platform for intelligent agents," CoRR, vol. abs/1809.02627, 2018. [Online]. Available: http://arxiv.org/abs/1809.02627

[19] F. Peng and J. Zhai, "A mobile augmented reality system for exhibition hall based on vuforia," in 2017 2nd International Conference on Image, Vision and Computing (ICIVC), 2017, pp. 1049-1052.

[20] A. Azanha, A. R. T. T. Argoud, J. B. de Camargo Junior, and P. D. Antoniolli, "Agile project management with scrum: A case study of a 
brazilian pharmaceutical company it project," International Journal of Managing Projects in Business, 2017.

[21] D. Owens, J. W. Merhout, and D. Khazanchi, "Project management assurance in agile projects: Research in progress," MWAIS 2018 Proceedings, pp. 17-18, 2018.

[22] N. Bolloju, S. L. Alter, A. Gupta, S. Gupta, and S. Jain, "Improving scrum user stories and product backlog using work system snapshots," in AMCIS, 2017.

[23] M. Adnan and M. Afzal, "Ontology based multiagent effort estimation system for scrum agile method," IEEE Access, vol. 5, pp. 25 993-26005, 2017.

[24] S. Semenkovich, K. O.I., and K. Degtiarev, "A modified scrum story points estimation method based on fuzzy logic approach," Proceedings of the Institute for System Programming of the RAS, vol. 29, pp. 19-38, 012017.

[25] Y. Wang, J. Ramadani, and S. Wagner, "An exploratory study on applying a scrum development process for safety-critical systems," in International Conference on Product-Focused Software Process Improvement. Springer, 2017, pp. 324-340.

[26] R. Paul and L. Behjat, "Using principles of scrum project management in an integrated design project," in Proceedings of the 15th International CDIO Conference, 2019, pp. 716-729.

[27] L. Gonçalves, "Scrum," Controlling \& Management Review, vol. 62, no. 4, pp. 40-42, 2018.

[28] V. T. Nguyen and T. Dang, "Setting up virtual reality and augmented reality learning environment in unity," in 2017 IEEE International Symposium on Mixed and Augmented Reality (ISMAR-Adjunct), 2017, pp. 315-320.

[29] M. Sarosa, A. Chalim, S. Suhari, Z. Sari, and H. Hakim, "Developing augmented reality based application for character education using unity with vuforia sdk," in Journal of Physics: Conference Series, vol. 1375, no. 1. IOP Publishing, 2019, p. 012035.

[30] A. J. R. Desierto, A. S. A. Reciña, J. C. T. Arroyo, and A. J. P Delima, "Goonar: A bilingual children storybook through augmented reality technology using unity with vuforia framework," International Journal, vol. 9, no. 3, 2020.
[31] O. Comber, R. Motschnig, H. Mayer, and D. Haselberger, "Engaging students in computer science education through game development with unity," in 2019 IEEE Global Engineering Education Conference (EDUCON), 2019, pp. 199-205.

[32] B. A. A. Ammourah and S. A. Pitchay, "Challenges of applying scrum model and knowledge management for software product management," in RITA 2018. Springer, 2020, pp. 123-130.

[33] S. Chapagain, "Application development with vuforia and unity3d," 2018.

[34] E. Cieza and D. Lujan, "Educational mobile application of augmented reality based on markers to improve the learning of vowel usage and numbers for children of a kindergarten in trujillo," Procedia Computer Science, vol. 130, pp. 352-358, 2018. [Online]. Available: https://www.sciencedirect.com/science/article/pii/S18770 50918304046

[35] A. Tupia-Astoray and L. Andrade-Arenas, "Implementation of an e-commerce system for the automation and improvement of commercial management at a business level," International Journal of Advanced Computer Science and Applications, vol. 12, no. 1, 2021. [Online]. Available: http://dx.doi.org/10.14569/IJACSA.2021.0120177

[36] A. Carrion-Silva, C. Diaz-Nunez, and L. Andrade-Arenas, "Admission exam web application prototype for blind people at the university of sciences and humanities," International Journal of Advanced Computer Science and Applications, vol. 11, no. 12, 2020. [Online]. Available: http://dx.doi.org/10.14569/IJACSA.2020.0111246

[37] R. Arias-Marreros, K. Nalvarte-Dionisio, and L. Andrade-Arenas, "Design of a mobile application for the learning of people with down syndrome through interactive games," International Journal of Advanced Computer Science and Applications, vol. 11, no. 11, 2020. [Online]. Available: http://dx.doi.org/10.14569/IJACSA.2020.0111187

[38] M. J. Mbuh, R. Mbih, and C. Wendi, "Water quality modeling and sensitivity analysis using water quality analysis simulation program (wasp) in the shenandoah river watershed," Physical Geography, vol. 40, no. 2, pp. 127-148, 2019. [Online]. Available: https://doi.org/10.1080/02723646.2018.1507339 